\title{
ERP System Course as a Facilitator for Students' Integrated and Integrative Thinking Mindset
}

\author{
Vasile Paul Bresfelean 1,2 , Adriana Tiron-Tudor 1,*, Ramona Lacurezeanu 1,*, \\ Claudia Andreea Bresfelean ${ }^{1}$ and Gabriela Mihaela Muresan ${ }^{1}$ \\ ${ }^{1}$ Babes-Bolyai University, Cluj-Napoca, Romania \\ ${ }^{2}$ George Emil Palade University of Medicine, Pharmacy, Science, and Technology, \\ Targu Mures, Romania \\ paul.bresfelean@econ.ubbcluj.ro,adriana.tiron@econ.ubbcluj.ro, \\ ramona.laurezeanu@econ.ubbcluj.ro, andreea.bresfelean@econ.ubbcluj.ro, \\ gabriela.muresan@econ.ubbcluj.ro
}

\begin{abstract}
Our present study proposes and tests a new ERP course. The course curricula makes use of an ERP SaaS application and an eLearning platform. The teaching approach is innovative, based on an integrated and integrative thinking in order to provide to the students the best experience with on-line simulation of business processes of a virtual company and create a favorable context for students' integrated and integrative thinking mindset. The whole package of training is the result of a close collaboration between academia, ERP providers and practitioners. The results of the study highlight the students' responsiveness to this type of learning and positive feedback concerning the content, following the learning integrated solutions that facilitate an integrated management based on an integrated thinking strategy at the company level, and moreover, an integrative thinking.
\end{abstract}

Keywords: ERP system, case studies, curriculum, assessments, eLearning platform, survey.

\section{Introduction}


Nowadays we live in an information society where the intensive use of information has a significant social and economic impact in all spheres of human existence (Beranič \& Heričko, 2019; Sánchez-Prieto et al., 2021; Sobral \& Sobral, 2021; Tiron-Tudor et al., 2021). The digital age has left its mark on the process of education, while Internet, Information, and Communication Technologies (ICT) have an undeniable role in most teaching and learning processes for higher and undergraduate education. In this context of digitization, more and more educational entities bring Enterprise resource planning (ERP) systems in their curricula due to labor market requests and to ERPs' high educational value (Beranič \& Heričko, 2019; Lacurezeanu \& Bresfelean, 2021; Leyh et al., 2012). Moreover, more and more companies, NGO and public sector entities also choose to implement an ERP system for all their administrative activities, due to the integration of all functions and processes of an organization (Antonucci et al., 2004). ERP systems have a crucial role in many industries. Driving forces include dramatic changes in the business environment, increased organizational complexity and great amounts of information to handle (Alves \& Matos, 2013).

Higher education could thus potentially benefit from adopting ERP systems in their curricula, notably in business and information systems classes (BecerraFernandez et al., 2000). This would prepare students for their future career, and the new requirements of the labor market.

Based on these considerations and the authors' experience on labor market research studies, information systems and teaching, the study develop a new course, called IERPIS (Integrated ERP Information Systems). The new course technological support is an ERP SaaS (Software as a service) application and an eLearning platform with materials, case studies, problems, assignments and on-line tests in order to provide students with the best experience in ERP systems within an on-line simulation training. Moreover, this new approach intention was to create a favorable context for students' integrated and integrative thinking mindset that let them to understand the whole entities process in their interconnection and to develop the ability to generate creative solutions.

In the next sections, we present a state of knowledge in the area of ERP use in business education, the creation of IERPIS, methodology used to evaluate the project's success, results, discussions and conclusions.

\section{ERP Utility in Business Education}

An Enterprise Resource Planning (ERP) system unites all departments of a company under one "software umbrella", including modules specific for production, accounts receivable and payable, order entry, general ledger, purchasing, human resources, warehouse, transport etc. (Shehab et al., 2004).

The fact that an ERP system includes all these modules and converges them into a common database, integrating data, considered as a single source of truth, makes 
this type of system have great improvements over previous developments (Bradford \& Florin, 2003). ERP systems are largely adopted by the companies and organizations all over the world, due to a large variety of advantages (Alves \& Matos, 2013; Bologa, 2007). We mention: quality information, adaptability, scalability, improved response time, user friendly interfaces and diminished dependence on paper, the avoidance of data and operation redundancy (Alves \& Matos, 2013) openness for e-business, lower costs, processing time, complexity and supplier dependency (Bologa, 2007). While in education institutions, we can mention the customized modules, lower administrative cost, joining data and processes linked to students, teachers and administration, meeting governance requirements, and improved decision-making. Furthermore, innovative technologies that start to be integrated with ERP systems, namely Robotic Process Automation (RPA), Artificial Intelligence (AI), Big Data, Cloud, Blockchain, etc., lead to a continuous modernization of these systems and a maintenance in rhythm with the super technological times (Yoon, 2020).

The growing variety of ERP systems makes it increasingly complicated for small and medium-sized enterprises (SMEs) to find the "right" software (Lacurezeanu \& Bresfelean, 2021) and then employ the right professionals for the designated system. Looking at the labor market in last years, we could see a growing demand for specialists to implement and administrate ERP systems and operate them according to each business (Humpl, 2020), who are somehow missing in a sufficient and qualitative number, although for years universities have been organizing courses in partnership with ERP providers. On the other hand, investment decisions about the adoption, updating or modification of ERP systems require specialized knowledge and skills, appropriate to the specifics of the company. This is very important, since errors that appear during the processes of selecting, implementation or maintenance of ERP systems are capable of producing financial drawbacks or disasters (Bresfelean et al., 2015).

In order to prevent such kind of setbacks, it was considered necessary to have a solid education regarding ERP systems among business students (BecerraFernandez et al., 2000; Cohen, 2005; Leyh et al., 2012). Some of the main objectives of promoting ERP courses are as follows: preparing students for their future business administration career and the need for ERP manufacturers that students understand their products at the earliest opportunity, due to the fact that they will later handle these systems or have jobs in companies that will affect directly investment decisions (Hepner \& Dickson, 2013; Leyh et al., 2012).

An ERP course is justified in business education by the diversity and interdisciplinary nature of the systems. In addition, such a course provides students with a broader and deeper understanding of how businesses operate, implement and use technology, with the clear aim of improving operations (Gerogiannis \& Fitsilis, 2006). The courses have special characteristics due to the technical complexity and 
the entailed skills: technical on the one hand and business-related on the other. Enterprise Resource Planning represents a valuable area in economic higher education but its teaching may be hampered by application-specific technical issues (Brehm et al., 2009).

There is a growing demand for trained ERP graduates that pressures higher education institutions to embrace ERP education in their curricula (Hepner \& Dickson, 2013). Since modern ERP systems have been part of the academic programs for over a decade (Hardaway et al., 2016; Wang \& Hwang, 2011; Wimmer \& Hall, 2016) it is largely deemed that students with ERP competences have superior employment prospects, therefore validating the value of ERP presence in the curriculum. Leyh et al. (2012) believe that one of the main objectives of utilizing ERP systems in academic courses is to warm up students for their future career by offering them no less than the general idea to ERP systems.

In recent years, there were research studies all over the world conducted on ERP courses in higher education. Dalveren (2014) studied the integration of ERP eLearning model into the university curriculum and presented some ERP eLearning models.

Magnusson et al. (2009) present the collaboration between School of Business, Economics and Law at the University of Gothenburg and Industry, which have jointly designed an ERP teaching program. The general idea behind of the course elaborates an outline to process orientation and associations to ERP systems, brief lessons in the ERP system focusing on specific business process. They used Microsoft SharePoint platform in which the consulting company created wideranging process maps, linked to all required directions for every process. Participants had also unrestricted access to install the ERP system (Magnusson et al., 2009).

In accordance with Xinxiang University, an ERP is more than a Management Information System (MIS), more than a combination between enterprise management and information technology, but comprises several technologies in order to standardize enterprise management, thus altering our way to think management (Y. Zhang, 2011). The authors of this study appreciated that the whole process, from teaching (content and teaching organization, methods) to the evaluation, must be reconsidered, reorganized, while selected teaching methods should be suitable to the new features. Thus, at the aforementioned university, the teaching of an ERP aimed at a course: of concepts and principles, ERP operation on the financial modules and on Supply Chain Management (SCM), install the main ERP modules, essential maintenance (Y. Zhang, 2011). Raicu et al. (2015) presented the most important aspects of innovation in Engineering Education and tried to improve the concept of eLearning using innovative technologies. Based on Madar ERP system developed in King Saud University in Riyadh, Saudi Arabia, Aldayel et al. (2011) try to identify the main success aspects for ERP in higher 
education institutions. Moreover, for Business Administration and Accounting students, ERP knowledge becomes a mandatory skill in many countries and universities, required by the employers (Becerra-Fernandez et al., 2000).

The ERP systems' adoption in higher education curricula started some years ago, when few academics have detailed knowledge of Enterprise Resource Planning ((Becerra-Fernandez et al., 2000) and was quite slower (Magnusson et al., 2009) due to universities' uncertainty in investigating how to use ERP in their curriculum (Duc, 2013; Hawking et al., 2008; Zornada \& Velkavrh, 2005). Due to the large presence on the market of ERP systems encompassing diverse technologies and philosophies, universities may have difficulties in selecting the "right" number systems, in what way to integrate them in the curricula and in what manner, or how deep should be taught (Leyh et al., 2012). Students prefer university with strong brands (Duc, 2013; Sung \& Yang, 2008) and influence their existing and future colleagues in a large manner.

Some authors (Z. Zhang et al., 2005) highlight the need of selecting proper course content and teaching methods for developing ERP curricula, others (Bradford \& Florin, 2003; Scott, 1999) signal the fact that ERP adoption is slowed down by complexity factors determining a challenging learning curve, while technical compatibility and compatibility in general, strongly helps it. As a general trend of the last decade, ERP practitioners and academia (Aldayel et al., 2011; Dalveren, 2014; Hardaway et al., 2016; Hepner \& Dickson, 2013; Wang \& Hwang, 2011; Wimmer \& Hall, 2016) bring to light the importance of novel and innovative programs that embrace ERP systems courses in higher education institutions. Based on these ideas related to the importance of ERP courses, a number of factors emerge the complexity of the educational phenomenon, the necessary technical and training efforts, the particularity of each institution versus the teaching methods approached, and the necessity of a continuous improvement of the ERP curricula and methods. In this context of the importance of ERP education for top higher education, we consider that our research conducted over 4 years of study meets the ideas of the research literature, enriches it, and the university practice.

\section{Diffusion and Adoption of Innovation in Education}

Innovation diffusion creates a comfortable and generous theoretical framework for researchers that have studied innovations in different domains from a variety of angles. In the area of technologies, diffusion of innovation theory issue by Rogers (2003) was employed to explain for example the role of innovation diffusion factors on the implementation success of ERP systems (Bradford \& Florin, 2003).

Furthermore, our study is framed from a theoretical point of view by the innovation diffusion theory (Meade \& Islam, 2006; Scaife \& Rogers, 1996) because introduce new approach in teaching ERP for business education. The followed aspects reveal the innovation of the course. First, the balanced input of the academia 
and practitioners in the course creation bring students in real life situations. Second, the teaching methods are based on developing an integrative thinking, (Martin, 2007). Integrative thinking a major effect in the classroom - in students' learning, skill development but also on teachers' pedagogy being able to generate eloquent learning practices that reinforce students' skills for solving problems by unlocking thinking and problem solving in classes, and assists students to participate in realworld problem solving. The most important element (Martin, 2007) of this realworld problem-solving is that it invites students into substantially eloquent and focused learning occasions that determine deep learning and well-being.

In our study, we aim to show how the students perceive this course as an innovative one, useful for building their skills and capabilities for a future carrier in business administration. Further, by our longitudinal data analyses over a 4 years period, including 4 cohorts of students, the study demonstrates the innovation diffusion, proved by the increased number of voluntary participations in the course proving the positive perceptions of students communicated to others using informal channels of communications, the student interest and involvement in course and seminar activities.

Our course implementation followed Rogers' (2003) conceptualized five phases, namely:

(1) Knowledge, the professors team started to collect information about different ERP and discuss with practitioners about ERPs features, and then about a practical course design, then they started to elaborate the course and seminar curriculum

(2) Persuasion, taking into consideration the five pivotal characteristics that influence innovation adoption: (a) Relative advantage underline the degree to which an innovation is perceived by a potential adopter as of higher value than the idea it succeeds. (b) Compatibility is about the extent of being in line with current values, past knowledge, and requirements. (c) Complexity concerns the degree to which an innovation is seen as comparatively hard to comprehend and utilize. (d) Trialability involves how much the potential adopter can experiment. (e) Observability is related with the degree to which innovation results are observable or communicated to others in the social system. In our case the informal channel of students' communication, word-of-mouth was extremely efficient in promoting the course.

(3) Decision, the course was proposed, presented and approved in the department to be included in the educational offer.

(4) Implementation, starting with the year of study 2017, the course was included in the faculty educational offer as an optional course.

(5) Confirmation, by the students' attendance, implication and feedback.

Bearing in mind the need to adapt to the technological changes that have occurred in the construction of an ERP, the problems incumbent on their adoption and use of an integrated system, we have adhered to the ideas of the theory of integrative thinking. This integrative thinking applied in teaching will develop for students, 
even in the incipient form, the ability to constructively cope with the tension of opposite ideas that appear in real life, generating a creative resolution of tension in the form of a new idea, containing elements of all ideas appeared in demersal to solve the problem (Riel \& Martin, 2017).

\section{Main Idea behind the ERP System Course}

The insertion of ERP systems in business education programs is vital today (Noaman \& Ahmed, 2015), as part of the curriculum (Blount et al., 2016; Iriberri et al., 2015) in order to prepare candidates for their future career in the local and national industry (Shanneb, 2020; Sinha \& Singh, 2020). We developed IERPIS as a mixt concept under the umbrella of the ERP Systems course, including an ERP SaaS (Software as a service) application, an eLearning platform, materials, case studies, problems, assignments and on-line tests in order to provide to the students with best experience in ERP systems within an on-line simulation background.

In the design and development process of the new course, we relied on these parts (Fig. 1):

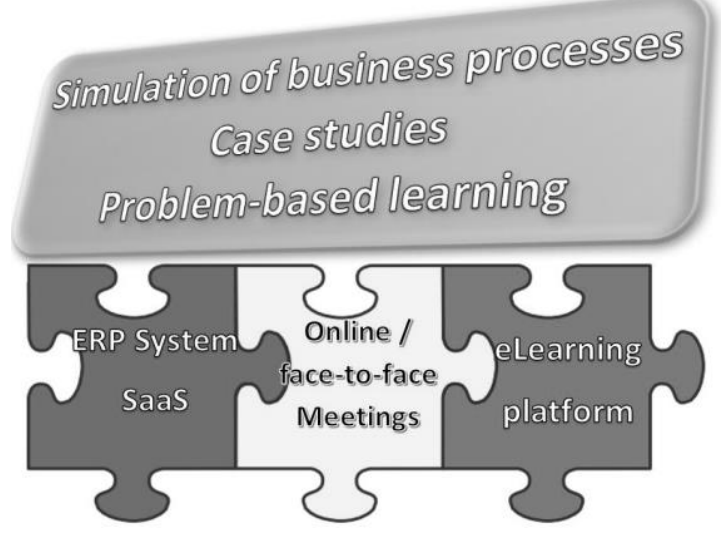

Fig. 1: IERPIS projected functional structure

The ERP system hosted by a university partner company as a SaaS cloud application. The application is fully functional being designed for company's endusers and clients, delivered over the web. It does not present the limitation of demo versions; thus, the teaching staff and students are able to benefit entirely from the software platform: each student has his/her own virtual company that can be fully administered throughout all business processes of a real-life organization. IERPIS relies on problem-based learning and the simulation of business processes based on case studies created together by academia and practitioners.

We wanted our students to move forward from learning plain accounting software to experience the business processes of companies and have the opportunity to work with information that is more complex and systems that manage these processes. Beyond teachers' and management team's intentions, we 
wanted to find a high-quality software solution, already proven on the national and even international market, but also to benefit from the experience and know-how of the company that has developed and implemented that software. We took into account the willingness of the company to enter into a partnership with the university, the availability of its specialists to work closely with our teaching staff for: software installation, settings, development of case studies eLearning materials, but also for their physical presence to some courses and laboratories. We strongly believed that the presence of specialists with proven experience in developing and implementing an ERP system our students will see beyond the theoretical aspects presented during face-to-face meetings and courses and will benefit from the transition to a modern software and from interactive simulations based on business processes. We also took into consideration a limited university budget for acquiring basic SaaS.

Table 1: ERP selection criteria

\begin{tabular}{cl}
\hline Criteria & ERP \\
\hline $\begin{array}{c}\text { Functionality } \\
\text { and }\end{array}$ & $\begin{array}{l}\text { Modules available in a full integrated system: Accounting and Financial, } \\
\text { Human Capital Management, Manufacturing and Distribution, Materials } \\
\text { Integration } \\
\end{array}$ \\
$\begin{array}{c}\text { Management, Sales and Inventory Management, Supply Chain Management, } \\
\text { Customer Service Management }\end{array}$ \\
\hline Deployment & $\begin{array}{l}\text { Software as a Service (SaaS) application - ERP deployed over the Internet, } \\
\text { Web access, one to many model, hosted and managed on providers servers, } \\
\text { allows integration with eLearning platform and mobile devices }\end{array}$ \\
\hline Training and & $\begin{array}{l}\text { Maintenance, Phone, Email, Training sessions with our teaching staff, case } \\
\text { studies and lab materials created together with the teaching staff, specialists } \\
\text { present to several courses, even after-hours support }\end{array}$ \\
\hline Costs & $\begin{array}{l}\text { Free software license, cloud hosting, support, maintenance and training, free } \\
\text { upgrades and legislation updates }\end{array}$ \\
\hline
\end{tabular}

After a rigorous analysis, taking in consideration specific methods for ERP selection (Haddara, 2018; Kilic et al., 2015; Lacurezeanu \& Bresfelean, 2021; Zeng et al., 2017), we chose Clarvision ERP software solution founded on the criteria presented in Table 1. We took into account all analysis factors, the company's stateliness to the local and international community, its management and employees' availability of involvement in educational projects, the complex and complete software solution that was offered (without limitations, such as evaluation copy and demo version) and also future collaboration prospects

eLearning platform - contains the support materials for the courses (theoretical part) and laboratories (the practice), inspired by the life real economic problems that students must solve and steps (hints and tips), interactive participation, live discussions, quizzes, evaluation, feedback.

On-line / face-to-face meetings - courses and seminars/laboratories where we present the case studies to work on and the simulation of business processes. 
This trio of aforementioned factors are the pillars of this course, coming together to help the smooth running of educational processes. First, the supporting materials in electronic format are posted on the eLearning platform; here we consider course documents and laboratories in .pptx and .pdf format, and video materials and tutorials to support students in solving the tasks received. Together with these, on the educational platform we have live chat and forum, where students can post questions to which teachers and other participants can answer in real time. Prior to the problems with the COVID-19 pandemic, the meetings (courses \& labs) were held face-to-face, but since March 2020 we have adapted to home working, teaching and learning, and all the meetings have since taken place online through Zoom video conferencing.

The connection to the ERP system is secured by means of Virtual Private Network (VPN) to protect both the data of the participants and the infrastructure of the partner company (Fig. 2). Students register at the beginning of the semester in an online form to receive access credentials to the VPN and the ERP system. The connection process is made in 3 steps: a) VPN connection - everyone installs a VPN client on their own laptop, computer or mobile device; b) Login to Windows Server 2019; c) Connection to Clarvision ERP.

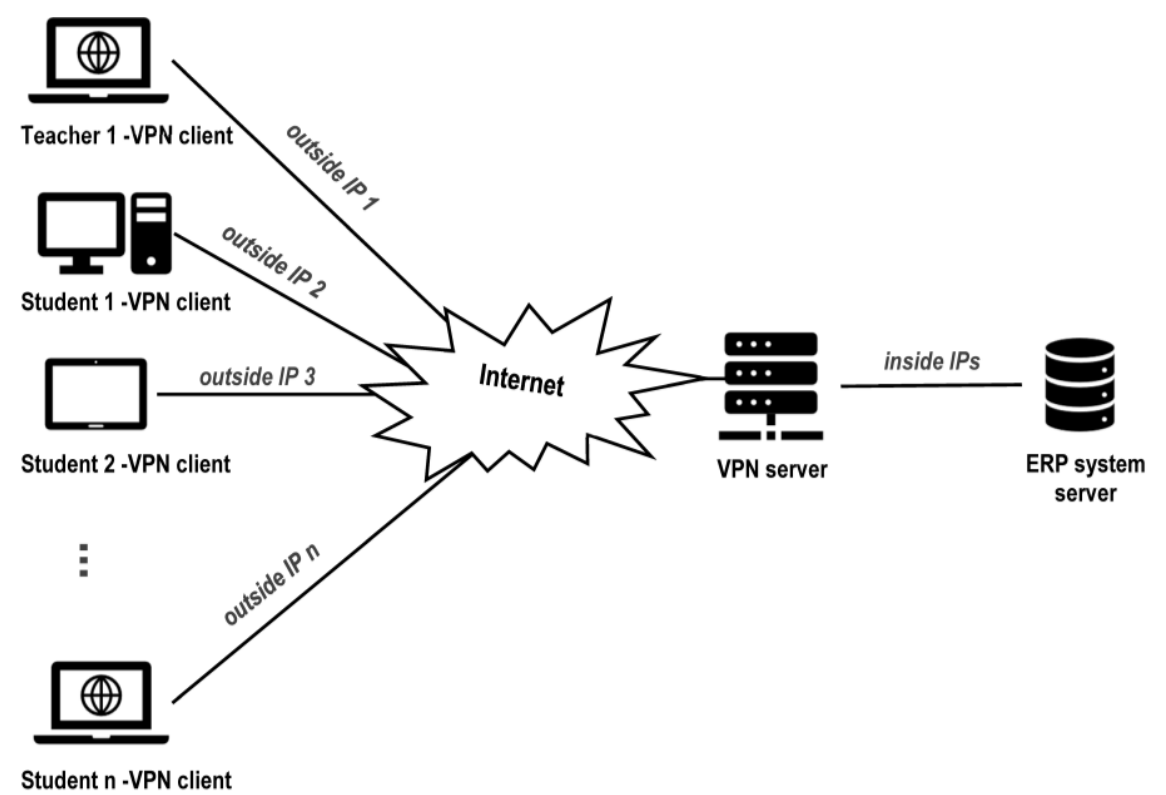

Fig. 2: Connection to the ERP system

After connecting to the ERP system, students have the opportunity to choose two companies: a company that already includes solved examples that they are able to consult, and another company with only basic data on which they have full administration rights. On the latter, they will carry out the simulation of business 
processes based on the explanations from the online meetings, and on the documents and video materials posted on the eLearning platform. On this platform assignments are posted with a specific schedule to be completed, and at the end of the semester the final theoretical test is carried out in the form of multiple choice / open questions.

In the process of developing this course, we were prepared long for work from home, because both the eLearning platform and the cloud-based ERP system can be accessed from any location in the world, both by teachers and students, not being related to physical presence in classrooms of the higher education institution. Only the face-to-face meetings have been fully translated into the online environment, through the Zoom video conferencing application, which has led to a total transition to the online environment in the last year.

\section{IERPIS Curricula}

We prepared the IERPIS detailed syllabus (Table 2) which covers general data on the higher education institution hosting the degree programs, specific details and characteristics of the study program and the study cycle. First two sections of the syllabus include information about the study program and about the course while the next section elaborates the estimated time (teaching hours per semester).

Table 2: Course detailed initial syllabus. Section 3 - Total estimated time (hours /

\begin{tabular}{|c|c|c|c|c|c|}
\hline \multicolumn{6}{|c|}{ semester) } \\
\hline 3.1 Number of hours per week & 4 & $\begin{array}{l}\text { out of which: } 3.2 \\
\text { Course }\end{array}$ & 2 & $\begin{array}{c}3.3 \\
\text { seminar/laboratory }\end{array}$ & 2 \\
\hline $\begin{array}{l}\text { 3.4 Total number of hours in the } \\
\text { curriculum }\end{array}$ & 48 & $\begin{array}{l}\text { out of which: } 3.5 \\
\text { Course }\end{array}$ & 24 & $\begin{array}{c}3.6 \\
\text { seminar/laboratory }\end{array}$ & 24 \\
\hline \multicolumn{5}{|l|}{ Time distribution } & Hours \\
\hline \multicolumn{5}{|c|}{ Study based on textbook, course support, references and notes } & 21 \\
\hline \multicolumn{5}{|c|}{ Additional documentation in the library, through specialized databases and field activities } & 10 \\
\hline \multicolumn{5}{|c|}{ Preparing seminars/laboratories, portfolios and reports } & 15 \\
\hline \multicolumn{5}{|l|}{ Tutoring } & 3 \\
\hline \multicolumn{5}{|l|}{ Assessment (examinations) } & 3 \\
\hline
\end{tabular}

3.7 Total hours for individual
study

3.8 Total hours per semester $\quad 100$

3.9 sNumber of credits 4

For IERPIS we considered 2 hours of courses and 2 hours of seminar / laboratory every week, and also specific timetables related to: study centered on textbook, course support, bibliography, notes, additional study in the library with access to databases and field activities, preparing seminars/laboratories, reports, portfolios, 
tutoring, assessment (examinations). In the IERPIS detailed syllabus we also pointed out several specific competences to be aimed, according with the labor market requirements (Table 3).

Table 3: Projected professional competences and transversal competences

\begin{tabular}{|c|c|}
\hline & \\
\hline $\begin{array}{l}\text { - Knowledge of ERP systems' paradigms } \\
\text { - Demonstrate the ability to use appropriate } \\
\text { concepts such as user groups, document flow, } \\
\text { process management, user management, } \\
\text { management analysis; } \\
\text { - Understand the importance of implementing ERP } \\
\text { systems in companies; } \\
\text { - Demonstrate the ability to analyze and interpret } \\
\text { synthesis data specific to ERP systems; } \\
\text { - Acquire abilities to analyze and evaluate the ERP } \\
\text { solutions present on the market; } \\
\text { - Develop skills to develop and elaborate ERP } \\
\text { solutions in the financial-accounting fields; } \\
\text { - Demonstrate the ability to integrate ERP systems } \\
\text { with other systems. }\end{array}$ & $\begin{array}{l}\text { - Develop specific activities to the software } \\
\text { implementation cycle, following the quantitative, } \\
\text { qualitative and economic efficiency aspects; } \\
\text { - Solve well defined economic problems in by } \\
\text { applying procedures integrated in complex } \\
\text { software systems; } \\
\text { - Define the requirements and characteristics to } \\
\text { update the information / software systems in the } \\
\text { organization; } \\
\text { - Use economic concepts in solving problems by } \\
\text { developing new information subsystems } \\
\text { systems in the organization; } \\
\text { - Use and evaluate analysis and design methods } \\
\text { based on well-established criteria for developing } \\
\text { information / software systems. }\end{array}$ \\
\hline
\end{tabular}

Taking into account a 12 weeks structure for the 6 th semester, we considered carrying out comprehensive weekly practices and plans, and the correlation of faceto-face meetings: theoretical courses with seminars / laboratory activities (Table 4).

During a couple of months period, we completed the structure of courses, seminars and bibliography, and in cooperation with NTT Data specialists we created a series of practical laboratory materials based on case studies and interactive simulations of business processes. These materials were uploaded on the eLearning platform, and the appropriate settings have been made in the Clarvision ERP application to allow our students a comprehensive experience of a proven ERP solution. Each student received a newly created user name and a password for the eLearning platform and for the ERP application. Moreover, each of them had access to his/her own virtual company with full administrative rights and virtual business records resembling to a real business experience.

The ERP application and the eLearning platform are accessible from anywhere in the world; thus, the participants are not limited to school's labs and to its Intranet. Teachers received supervisor rights to follow and assess students' activities. NTT data representatives had super-administration rights for the ERP system in order to 
upgrade, maintain, install latest add-ons, and update the system to newest legislation amendments.

For the evaluation activities, we considered several aspects (Fig. 3), as follows:

- Practical assessment, following both weekly activities during seminar / laboratory hours but also an evaluation at the end of the semester with individual questions based on the case study developed on Clarvision ERP system.

- Theoretical assessment on the eLearning platform in the form of test of multiple choice / open questions.

Table 4: Course and seminar/laboratory weekly plans and correlations

\begin{tabular}{|c|c|c|}
\hline Week & Col & opics \\
\hline$\# 1$ & $\begin{array}{l}\text { Introduction to integrated information } \\
\text { systems (EAS/ERP) and utilized } \\
\text { technologies }\end{array}$ & $\begin{array}{l}\text { Establish the work plan and accommodate with the } \\
\text { integrated information systems; establish user } \\
\text { groups and access rights }\end{array}$ \\
\hline$\# 2$ & $\begin{array}{l}\text { ERP and BPR (Business Process } \\
\text { Reengineering) }\end{array}$ & $\begin{array}{l}\text { Setup and configure the enterprise, products, } \\
\text { partners, staff, banks, administration. }\end{array}$ \\
\hline$\# 3$ & 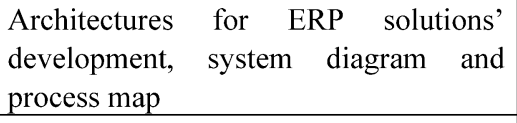 & $\begin{array}{l}\text { Initialize stock items - entries: invoices, notices, } \\
\text { invoice for shipping notices, orders to suppliers, } \\
\text { notices and invoices to orders }\end{array}$ \\
\hline$\# 4$ & $\begin{array}{l}\text { ategies for implementing an ERP in a } \\
\text { npany: software package selection, } \\
\text { nning, operation and maintenance }\end{array}$ & $\begin{array}{l}\text { ent activities. Document flow, } \\
\text { s. }\end{array}$ \\
\hline$\# 5-6$ & $\begin{array}{l}\text { Customer Relationship Management } \\
\text { and Knowledge Management in ERP } \\
\text { systems }\end{array}$ & $\begin{array}{l}\text { er and Supplier relationship management } \\
\text { operations. }\end{array}$ \\
\hline$\# 7$ & $\begin{array}{l}\text { al and accounting management } \\
\text { systems }\end{array}$ & inventory objects \\
\hline$\# 8$ & source management in ERP & $\begin{array}{l}\text { es and payroll management. } \\
\text { ategories of documents }\end{array}$ \\
\hline$\# 9$ & $\begin{array}{l}\text { Production Management and Supply } \\
\text { Chain Management (SCM) in ERP } \\
\text { systems }\end{array}$ & $\begin{array}{l}\text { Production management: planning, implementation, } \\
\text { monitoring production, ante calculation, after } \\
\text { calculation. Integration with the accounting module } \\
\text { and other modules }\end{array}$ \\
\hline $\begin{array}{l}\# 10- \\
11\end{array}$ & $\begin{array}{l}\text { Business Intelligence (BI) and } \\
\text { Electronic Commerce integration with } \\
\text { ERP systems }\end{array}$ & $\begin{array}{l}\text { Commercial operations management. Document } \\
\text { flow, Integration with the accounting module. } \\
\text { Inventory management }\end{array}$ \\
\hline$\# 12$ & Auditing ERP systems & $\begin{array}{l}\text { Managerial Analysis. Indicators, reports and } \\
\text { financial leverages }\end{array}$ \\
\hline
\end{tabular}

\section{Research Methodology}

Our paper design approach corroborates student perception concerning the new course based on a survey data collection with the eLearning platform data relating to the students' activities.

This online survey was intended for students to evaluate the course and the teaching processes, and is based on the configuration of eVALUate, an instrument 
conceived for higher education, which was substantiated and utilized in multiple discipline areas by many institutions from all around the world (Bodisco \& Palmer, 2020; Kumpas-Lenk et al., 2014; B. Oliver et al., 2008). The eVALUate instrument has a dual structure: first it presents with eleven scale items, then with another two items based on open-ended responses (Table 5), thus allowing the students to offer a thorough feedback on the course learning and teaching design.

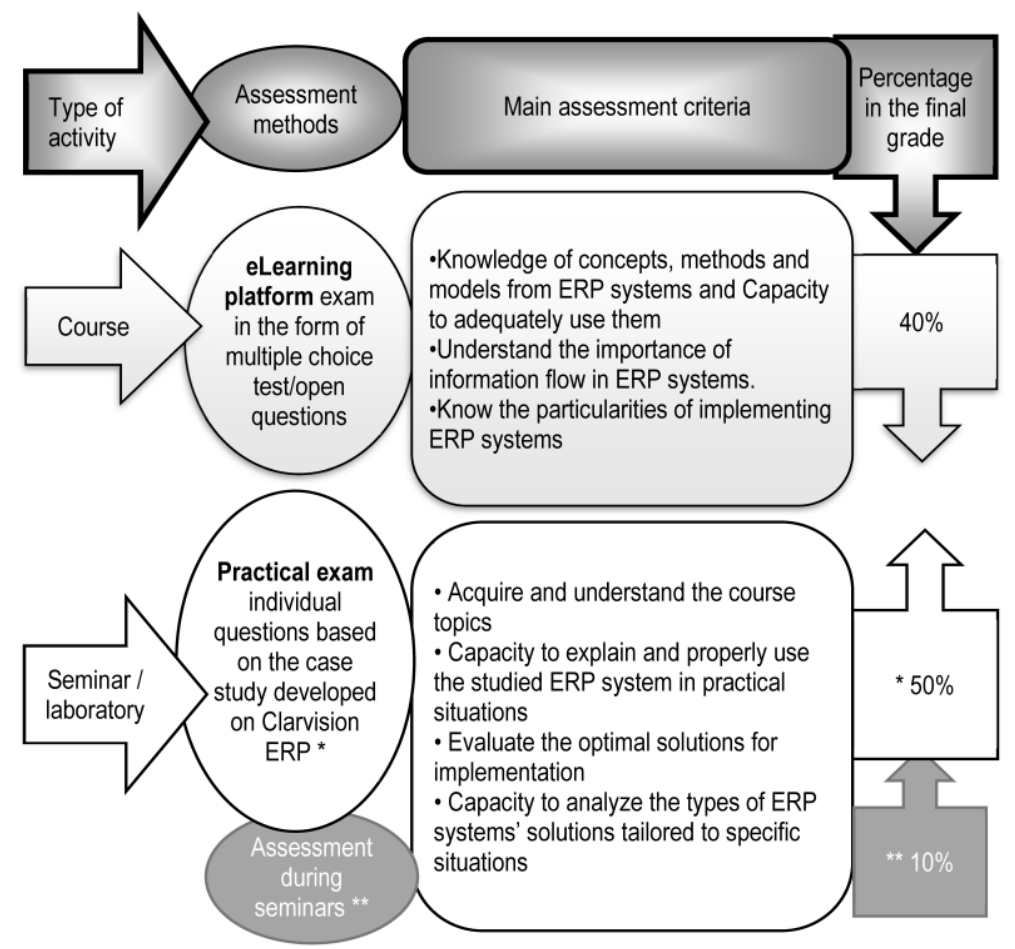

Fig. 3: IERPIS evaluation activities

Table 5: Structure of the eVALUate survey, from (Bodisco \& Palmer, 2020; KumpasLenk et al., 2014; B. Oliver et al., 2008) 


\begin{tabular}{cc}
\hline & Scale Items \\
\hline 1. & The learning outcomes in this unit are clearly identified. \\
2. & The learning experiences in this unit help me achieve the learning outcomes. \\
3. & The learning resources in this unit help me achieve the learning outcomes. \\
4. & The assessment tasks in this unit evaluate my achievement of the learning outcomes. \\
5. & Feedback on my work in this unit helps me to achieve the learning outcomes. \\
6. & The workload in this unit is appropriate to the achievement of the learning outcomes. \\
7. & The quality of teaching in this unit helps me to achieve the learning outcomes. \\
8. & I am motivated to achieve the learning outcomes in this unit. \\
9. & I make best use of the learning experiences in this unit. \\
10. & I think about how I can learn more effectively in this unit. \\
11. & Operall, I am satisfied with this unit. \\
\hline & What are the most helpful aspects of this unit? \\
2. & How do you think this unit might be improved? \\
\hline
\end{tabular}

The survey was posted on-line near the end of the semester and was voluntarily completed by the students after the exams' session. The results of the survey are anonymous, not being accessible by the teaching staff. The students were previously informed about all the confidentiality details, so that they could be able to complete the survey, without any fear of reprisal from their professors (Bodisco \& Palmer, 2020).

All the scale items are offered in the form of statements, and to each of them the respondents should specify their degree of agreement on a four-point scale: "Strongly disagree", "Disagree", "Agree", "and Strongly Agree". There is also an unbiased option "Unable to Judge" that can be selected as well. As for the two open-ended response items, these are in the form of questions to which students can give a free-form text answer.

The implementation of the eVALUate survey, its scale and open-ended items are robust due to substantial iteration and progress in the last years at several higher education institutions (Faisal Anwar, 2012; Kumpas-Lenk et al., 2014; B. Oliver et al., 2008; Tucker et al., 2013).

Therefore, it can be considered as a valuable, balanced and impartial system of measurement of students' engagement and satisfaction, and by all means it does not include any data to help detect the identity of the respondents.'

The response scales used by students to answer the first part of the survey are basically ordinal, this being common in many parametrical statistical methods, but its validity is not unanimously accepted (Carifio \& Perla, 2008).

But there are a number of studies that have shown that the analysis of ordinal scale data has an important practical utility, being founded on the parametric methods to "significant departures from the assumptions about the underlying data, including departures from normality and intervalness" that could appear in such 
data (Winter \& Dodou, 2010), (Norman, 2010).

In the Results section, we exemplify the use of mean response rating (as a score out of 4.0) for all the four years considered in our study, where we computed a $95 \%$ confidence interval for the tested items, and we discuss the experimental results of our research.

The eLearning platform was introduced to allow teachers to deliver more efficiently the main content of the course (learning materials in .pdf, .pptx format, video tutorials, additional links, assessment tasks, quizzes) while also promoting students' direct involvement through online forum and chat. On the other hand, logs extracted from Moodle and the ERP system are a tool to find / check / evaluate information when a student accomplishes an assignment, submits a task, posts messages on a forum/chat or tries / submits answers to a test (Table 6). In this logic, we used from Moodle logs the following activities with specific actions:

Table 6: Activities and actions on the eLearning platform, based on (Raga \& Raga, 2017), (Estacio \& Raga, 2017)

\begin{tabular}{cc}
\hline Activity & Action per activity \\
\hline \multirow{2}{*}{ Content access } & Course view \\
& Resource view \\
& Uploading assessment \\
\hline \multirow{2}{*}{ Evaluation } & Quiz view \\
& Quiz attempt \\
Engagement & Assign submit \\
& Forum view/add disc \\
\end{tabular}

Based on our previous studies (Lacurezeanu et al., 2018), the following evaluation pointers were developed:

a. Reading course materials,

b. Downloading assignment materials and finishing assignments,

c. Reading course materials, downloading assignment materials and finishing assignments,

d. Reading course materials, downloading assignment materials and finishing assignments, communicating on chat,

e. Reading course materials, downloading assignment materials and finishing assignments, communicating with via forum.

f. Reading additional bibliography provided on course eLearning platform.

Furthermore, derived from the research literature (Estacio \& Raga, 2017; Lacurezeanu et al., 2018; Raga \& Raga, 2017) and in relation to the course detailed syllabus, we analyzed the average time spent by a student for specific activities, logged in the ERP system and on the eLearning platform. For all four years of study, we analyzed the following indicators: 
1. The average time spent logged in the ERP system to complete each of the 6 assignments (that each year remained on the same topics)

2. The average time spent on the eLearning platform for specific activities: forum unit, chat unit, solving a quiz, course section \& resources

3. Average number of posts per forum unit and posts per chat unit.

The results and discussion section include a description of the students' groups involved in the course, students' feedback based on questionnaire responses and Data logs from the ERP application and the eLearning platform.

\section{Results and Discussion}

\subsection{Insights concerning the students group involved in the course}

Since the beginning of our study in 2017, the total number of students enrolled in the course increased year by year. In the first year of the analysis (Table 7) we had a good participation (140 students), mainly from full-time learning business programs, but also from those enrolled in distance/ part-time learning program.

In the second year we had a $15 \%$ increase in the number of students to 161 participants, mainly from students enrolled in distance/ part-time learning programs (24\%). In the third year the number of participants also increased but to a lesser magnitude, partially due to a smaller number of students from distance/ part-time learning programs, but we acknowledge the increased interest of students from fulltime learning students. Unluckily, in 2019 distance/ part-time learning students did not prefer this optional course ( $-19 \%$ decrease), principally due to its novelty but also because of a dose of fear regarding the difficulty specific to IT courses.

Table 7: Evolution of participants in 2017-2020

\begin{tabular}{c|c|c|c}
\hline $\begin{array}{c}\text { Year / Type of } \\
\text { study }\end{array}$ & Full-time learning & $\begin{array}{c}\text { Distance / part-time } \\
\text { learning }\end{array}$ & $\begin{array}{c}\text { Total number of } \\
\text { enrolled students }\end{array}$ \\
\hline 2017 & 94 & 46 & 140 \\
2018 & 102 & 59 & 161 \\
2019 & 126 & 48 & 174 \\
2020 & 176 & 73 & 249 \\
\hline
\end{tabular}

In the last year of the study, we had a very good increase of $43 \%$ to a total number of 249 participants from all specializations, both full-time and part-time learning. The growing interest might be explained by the: increasing the demand for specialized workforce on the IT market, the students' desire to learn something new in the interplay between business and IT, the interest for a software developed by a large company with a strong national and global presence, the practical / applicative side of the course, etc. 


\subsection{Students' feedback based on survey responses}

Each year the students enrolled in this course were asked to provide feedback. The number of enrolled students increased every year, as well as the number of valid answers to the survey (Table 8). The response rates were quite low, around an average of $29 \%$, but fall within the range of response rates reported in the research literature for these types of online surveys. Our survey is voluntary with anonymous data and we do not have the possibility to verify the representativeness of the group of respondents in relation to the total number of students enrolled in the course (Bodisco \& Palmer, 2020).

In Figure 4 we present the mean response ratings and the confidence intervals (95\%) for the 11 items of the survey for the four years of study taken into account. It demonstrates the receptivity of students to the course, by the increased number of participants each year, but also by the fact that the mean response ratings were increasingly higher for each year between 2017-2019, for almost all of the items (except item 5 where there was a slight drop of 0.05 in 2018). It indicates the continuous concern of the initiators of this course for its continuous improvement, and the fact that we made efforts to take into account all the observations and suggestions received from the participants.

Table 8: Mean response ratings for the 11 scale items of the survey

\begin{tabular}{|c|c|c|c|c|c|c|c|c|c|c|c|c|c|c|}
\hline Year & $\begin{array}{c}\text { No. of } \\
\text { enrolled } \\
\text { students }\end{array}$ & $\begin{array}{c}\text { No. } \\
\text { of } \\
\text { responses }\end{array}$ & $\begin{array}{c}\text { Response } \\
\text { rate }\end{array}$ & & 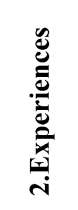 & 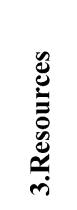 & 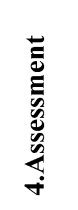 & 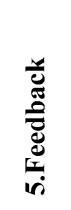 & & & 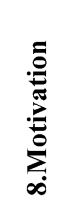 & 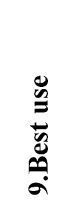 & 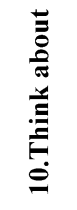 & 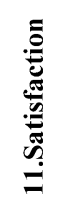 \\
\hline 2017 & 140 & 39 & $27.9 \%$ & 3.18 & 3.21 & 3.08 & 3.05 & 3.33 & 3.00 & 3.31 & 3.15 & 3.46 & 3.36 & 3.62 \\
\hline 2018 & 161 & 47 & $29.2 \%$ & 3.23 & 3.28 & 3.26 & 3.34 & 3.28 & 3.36 & 3.40 & 3.38 & 3.51 & 3.40 & 3.66 \\
\hline 2019 & 174 & 54 & $31.0 \%$ & 3.46 & 3.67 & 3.41 & 3.54 & 3.43 & 3.54 & 3.59 & 3.65 & 3.48 & 3.48 & 3.81 \\
\hline 2020 & 249 & 71 & $28.5 \%$ & 3.72 & 3.23 & 3.10 & 3.41 & 3.14 & 3.21 & 3.44 & 3.11 & 3.62 & 3.51 & 3.58 \\
\hline All years & 724 & 211 & $29.1 \%$ & 3.40 & 3.35 & 3.21 & 3.34 & 3.30 & 3.28 & 3.44 & 3.32 & 3.52 & 3.44 & 3.67 \\
\hline
\end{tabular}




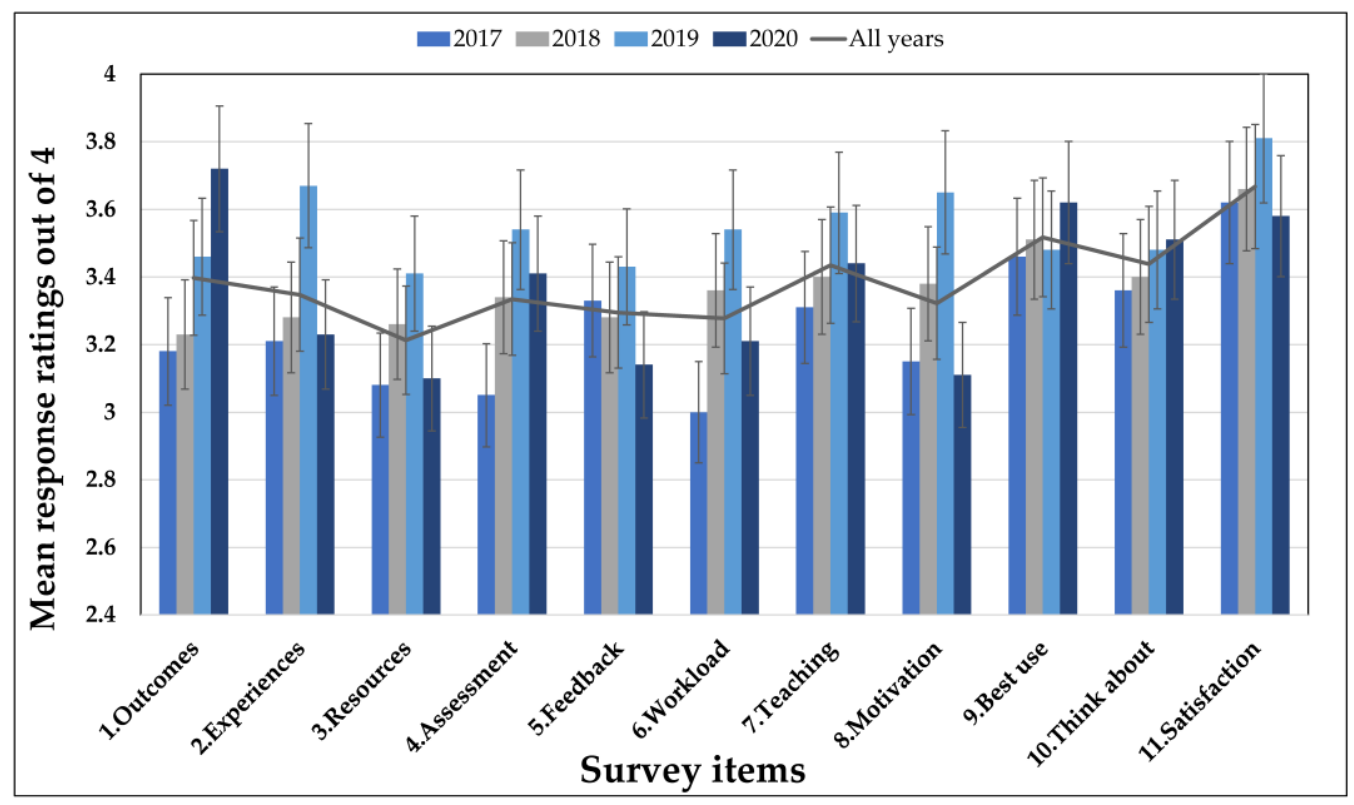

Fig. 4: Evolution of mean response ratings.

We remarked in the first year 2017 that there were lower mean response ratings for three of the items. For example, for item 6 (workload) mean rating was 3.00, a fact explained by some students by the multitude and high degree of difficulty for the tasks they received in this first year of the course. Teachers remedied this in the following years, gradually adapting workload to specific requirements, including tasks, independent learning, and group work. We detected the same thing in the case of item 4 (assessment) with 3.05 mean rating, when the students underlined the multitude and the high degree of difficulty of the assessment tasks (exam, homework, etc.), but also in the case of item 3 (resources). For the latter item, the students reported early connection problems to the ERP system. The initial difficulty of installing and setting up the VPN client, some connection problems due to the Internet provider were also mentioned. The existing outdated equipment in some laboratory classrooms, overloaded wireless routers at the university created also problems. All of them were not depend on teachers and a number of them were gradually resolved in the following years.

The 2017, being the first year, was an experimental year, the beginning, but it was an exciting effort from all participants, teachers and students, which made the course go on to be chosen by even more students and to be appreciated to a greater extent. The number of increased participants is also explained by students' appreciation transmitted word to mouth to their younger colleagues, who in the following years appeared in a larger number.

The dreadful pandemic that came suddenly, unannounced, somehow changed the rules of the game, the way of performing the teaching-learning processes. Due to 
the way this course was conducted, the eLearning platform and the ERP system in the cloud, it was not difficult to adapt to the working from home through Zoom video conferencing. However, it lacks that face-to-face, human touch, the live presence of teachers and students at courses and laboratories, the fast feedback and real-time support that was given to students, and perhaps all participants' presence of mind who enlivened the atmosphere in the classrooms. Of course, the general situation, the sudden lockdown, affected the general morale and optimism of the course participants, a fact also reported in the answers to the survey.

Even in these difficult conditions for everyone, the mean rating has increased even in 2020 for a few items (1.outcomes, 2.best use, 10.think about) or has remained greater or equal to mean rating from all years (4.assessment, 7.teaching). The other items experienced a decrease in mean rating; the most dramatic being items 3, 5 and 8. Needless to say, the low appreciation of item 3 (resources) has to do with the sudden way in which schools in our country were closed in March 2020, when both students and teachers were sent home due to the emerging COVID-19 pandemic. We had to continue the educational process, therefore adapt to online meetings, videoconferencing with tens and hundreds of participants, and it took a while for video conferencing software licenses to be purchased.

In order to support our students, we additionally made video materials and tutorials in which we presented concrete examples of solving tasks and exercises based on the ERP system. These were posted on the eLearning platform and on YouTube.

Unfortunately, even the feedback (item 5) given to the students, which at the face-to-face meetings was fast and in real time (and the teacher had the opportunity to promptly go through all the class participants, answer their questions individually and help them), has now undergone a transformation. Online video conferencing has somehow slowed the support given to students and the fact that sometimes the course ends and there are still problems to be solved. The teachers tried to counterbalance this fact and to answer the students' questions by email and directly on the eLearning platform (chat, forum). The motivation part (item 8) has also seen a sharp decline in the last year. Somehow it is comprehensible, when a young student tries to learn locked in the house, without being able to see his/her friends and colleagues, while people around you get sick and the news in the media are getting more and more gloomy and pessimistic. We, the teachers, tried to do our best for our students in these difficult conditions, by encouraging and supporting them in the best manner we could, although we were in the same situation. Given these special circumstances, we were fortunate and grateful to receive good feedback from our students, although some mean response ratings were dropping, others increased or remained at the level of the average of all years.

Many of the students involved in the survey also gave written answers to the two open-ended response items included, helping us to identify a few contours linked to 
the developing aspects of the course (Fig. 5). The students appreciated the content of the course "this course was very interactive", the learning process "interesting course, useful information, demonstrated/showed through examples for easier understanding, through diagrams", and "the multitude of concrete and real examples helped in achieving a better vision in what concerns the meaning of ERP". A great number of students appreciated the interaction with the business environment, more exactly with the employees from the ERP provider. Here are some students remarks: "I really appreciated the involvement of the professionals from the partner company"; and "the courses and laboratories presented by the professors and the professionals were interactive and in the same time we acquired useful information about business processes inside a company and the way in which it operates, something that was of great interest for us." The entire learning process was conducted in the presence of the professors, who, apparently, had "a pleasant way of teaching". In the last year of study, most of the students appreciated the video materials and tutorials ("the videos helped me big time in solving the tasks at home")

The negative aspects were concerned mainly with the complexity of the course and the assessments (especially in the first year of study), resulted from the multitude of new and technical concepts, the time ("it seemed e that the number of courses was too low") and aspects linked to the starting hour ("the course was scheduled at 8:00 AM"). In the last year, several participants affirmed to have missed the face-to-face meetings, and the motivation, the real-time feedback and support offered by the professors: "I wish we could all come back to school again, it is difficult to solve some of the tasks and be motivated without a real-time support".

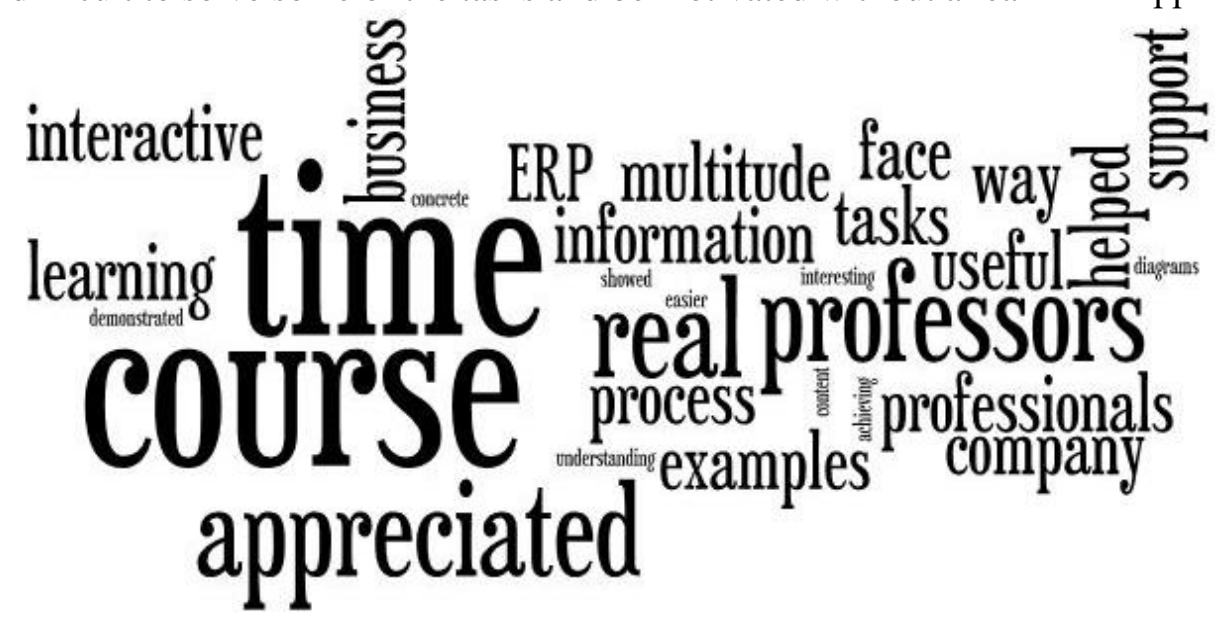

Fig. 5: Word cloud based on open-ended responses

\subsection{Data logs from the ERP application and the eLearning platform}

In each year of study, we were able to consult the logs from the ERP application and the eLearning platform. These systems are complementary: materials, tutorials, case studies, assignments were posted on the eLearning platform, and then solved 
by the students on the ERP system. At the start of a task, a student usually opens the VPN connection to the ERP application and also logs in the eLearning platform. Upon completion of the task the student closes the connection to the ERP SaaS application and logs off the eLearning platform (for a certain number of minutes of inactivity, the participant is logged off automatically).

Based on the logs from the eLearning platform, we noticed that the students have gradually used more the eLearning platform in the four years of the study. In the next lines, we present a summary of the main pointers about how students mainly use the resources from the eLearning platform:

a. Reading course materials - an evolution from $85 \%$ - $92 \%$ in $2017-2019$, to almost $99 \%$ in 2020. This was mainly because before the pandemic, most of the materials were also available in printed form in the classroom.

b. Downloading assignment materials and finishing assignments - an evolution from $72 \%$ in 2017 , to $89 \%$ in 2020 (there were a small number of students who did not finish all the assignments).

c. Reading course materials, downloading assignment materials and finishing assignments - a combination of the above pointers - there is still an evolution for the years of study (78\% in 2017 to $94 \%$ in 2020).

d. Reading course materials, downloading assignment materials and finishing assignments, communicating on chat. Although an important component of the live feedback offered to our students, chat was scarcely used in combination with the other resources, thus this pointer was not as high as the others were, although evolving from $20 \%$ in 2017 to approximately $40 \%$ in 2020.

e. Reading course materials, downloading assignment materials and finishing assignments, communicating with via forum - the forum was use even less than the chat in combination with the other resources, evolving from 14\% in 2017 to $30 \%$ in 2020 .

f. Reading additional bibliography provided on course eLearning platform - while main materials posted on the platform were rather complex, and cover all the topics and tasks of the course, teacher still posted some additional bibliography. Nevertheless, most of the students were content with the main materials, and scarcely read this bibliography, but it was still a small progress, from $17 \%$ in 2017 to almost $29 \%$ in 2020 .

The course included six assignments to be solved, which were graded by the teachers. We analyzed these grades compared to the activity on ERP system, and eLearning platform. Our university uses a 1 to 10 grading system: 10 is the best, 1 is the worst, while 5 is the lowest passing grade.

Table 9: Average time spent on ERP system and eLearning platform, and average number of forum posts and chat massages 


\begin{tabular}{|c|c|c|c|c|c|c|c|c|c|c|c|c|}
\hline \multirow[b]{3}{*}{ Year } & \multicolumn{10}{|c|}{ Average time spent on specific activities (in minutes) } & \multicolumn{2}{|c|}{$\begin{array}{l}\text { Average no. of } \\
\text { forum posts and } \\
\text { chat messages }\end{array}$} \\
\hline & \multicolumn{6}{|c|}{ ERP system } & \multicolumn{6}{|c|}{ eLearning platform - units and sections } \\
\hline & 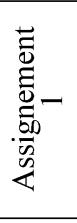 & 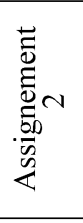 & 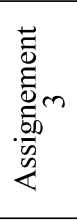 & 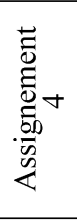 & 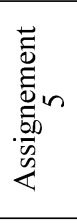 & 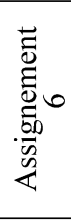 & Forum & Chat & Quizz & 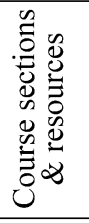 & $\begin{array}{c}\text { Forum } \\
\text { posts }\end{array}$ & $\begin{array}{c}\text { Chat } \\
\text { messages }\end{array}$ \\
\hline 2017 & 35 & 27 & 28 & 38 & 40 & 43 & 12 & 9 & 32 & 75 & 0.14 & 0.2 \\
\hline 2018 & 31 & 26 & 28 & 34 & 39 & 38 & 14 & 12 & 30 & 78 & 0.17 & 0.23 \\
\hline 2019 & 32 & 26 & 29 & 35 & 38 & 36 & 11 & 14 & 29 & 80 & 0.17 & 0.22 \\
\hline 2020 & 38 & 30 & 34 & 39 & 41 & 44 & 20 & 32 & 27 & 89 & 0.3 & 0.4 \\
\hline
\end{tabular}

In the first year of study 2017, we notice from Table 9 that on average a student spent 35 minutes connected to the ERP system to solve the first assignment received. This can also be explained by the fact that the students were not familiar with the system, although they benefited from the face-to-face support and a thorough introduction from the teachers. The time spent in the ERP system diminished on average for assignments 2 and 3, and grew for the last two (5 and 6) due to their increasing difficulty. In the second year of study 2018, we notice a decrease of the average time spent by a student in the ERP system to solve the first assignment, but also for the rest of the assignments for which the average time decreased or remained the same (in the case of the third assignment). This can be mainly explained by teachers' adjustment of the assignments, which, although they remained on the same topic, were perfected to respond to the students' observations expressed in the survey, both in the assessment and workload items, as well as in the open-ended responses. In the following year 2019, there is a stabilization but with a small variation of the average time spent in the ERP system around the same values, slightly higher for assignments 1, 3 and 4, approximately equal in the case of assignment 2, and lower for the assignments 5 and 6 .

In the last year of the 2020 study, the average time spent in the ERP system increased substantially compared to the previous year by 4-7 minutes for all six assignments, even if no assignment increased in difficulty. Based on the answers offered to the survey, especially open-ended response items, we can explain this by the absence of face-to-face meetings and the real-time feedback and support offered by the teachers. In previous years, these assignments could be done during laboratory classes in the classroom, students benefiting from the help of their teachers, with whom they consulted in any problem, and who were a real support for the participants. Due to the transition to working from home and online video conferencing, the waiting time has increased (following other students with other 
questions) and new specific problems appeared (connection problems, Internet speed, microphone, share -screen etc.). Teachers tried to compensate for this by an extensive presence on the forum and chat from the eLearning platform, and with prompt responses by email.

Regarding the presence on the eLearning platform, we notice that the participants were less active in the years 2017-2019 on a forum unit with a variation between 11 and 14 minutes on average per student (0.14-0.17 posts), and also on a chat unit with a variation between 9 and 14 minutes on average (0.2-0.22 posts). Of course, there were students who did not have any posts on both forum and chat, others consulted little or not at all the forum, while others were extremely active on the forum, posting pertinent questions to which the teacher or others colleagues responded promptly. In 2020, we found a high increase in the average time spent per forum unit compared to the previous year $(81 \%)$, while the chat time more than doubled (129\%). This could also be explained by the relocation of the entire educational processes in the online environment and that the forum and especially the chat are easy means of communication available to participants. As for the average time spent to solve a quiz, we observed a decrease from year to year, a fact explained by teachers' continuous adjustments made to the quizzes (increasing the degree of clarity, decreasing the difficulty of some questions in a quiz), according to the open-ended response items in the survey. Instead, the average time spent on a course section where all the resources and documentation necessary for an assignment are posted has constantly increased, with a more significant growth in the last year 2020 (11\% compared to the previous year).

In conclusion, we can express our presumptions, which integrate the aspects found over time regarding the evolution of our project. The ERP course facilitates the learning process of the students through the partnership created between the university and the business environment. The interest and the motivation for gaining new knowledge were captured through the declared responses. On the other hand, negative aspects are generally oriented towards time insufficiency and the lack of real-time face-to-face support in the last year of study 2020.

From the starting year 2017, the course obtained the anticipated learning outcomes and was well received by students, being improved from year to year based on the feedback provided through the survey. Therefore, after the first survey we adapted the workload and assessments in order not to overload the students' program and to meet their desires. Technical problems related to Internet access and outdated equipment in the laboratory rooms were largely solved by 2019. For the problems reported during the first year of the pandemic (2020), about insufficiency of feedback and real-time support, we tried to compensate with materials and video tutorials, by email, chat and forum. Of course, there is still room for improvement even in the difficult conditions of the pandemic, we still hope to return to the classrooms soon, but if this does not happen, we will be prepared with new course 
improvements for online meetings and we will we seek to encourage and motivate our students the best way we can.

\section{Conclusions}

The theory of integrated thinking is closely related to practice. Teaching an ERP software involves a systemic thinking, which results both from the logic of the processes it computerizes and from the integrated construction of the component modules. The theory used in this paper (Abbott \& Nantz, 2012; Oliver et al., 2016; Riel \& Martin, 2017), comes to fill an area with few practical examples, that of integrated thinking in teaching an ERP course.

As teachers, every year we take on a new group of students, each bringing a unique mix of skills and learning experiences. As a result, for effective teaching, we are always looking for new approaches and strategies, such as diffusion of innovation in education. In this line of innovation, through the proposed work we bring novelties that consist in adopting integrative thinking both on the approach of lessons, examples, and through new formats for evaluating and monitoring student performance. We appreciate the contribution of our approach that it has implications both among our colleagues, teachers, and among ERP providers and ERP user companies.

Our present paper sums up the results of 4 years of practice in teaching an ERP course, a course designed both to facilitate better learning, for learning the necessary skills in the labor market, and to assess the adequacy of this approach to thinking.

The course was created with the clear intention of facilitating the use of a complex ERP system for undergraduate students, business specialization, bringing novelty to this category organized in our country. The evolution of our course was monitored in the form of a survey with eleven scale items, and two open-ended responses, thus offering our students the possibility of a thorough feedback on the course learning and teaching design, thus measuring their perception concerning the new course. Furthermore, we also conducted an analysis of specific logs from the ERP systems and the eLearning platform (reading courses, additional bibliography, downloading assignment materials and finishing assignments, communicating on chat, forum) and of the average time spent by a student for specific activities. This can provide us with relevant information for optimizing the educational processes and supporting our students in order to plan better their time dedicated to specific activities and learning time in general.

The results presented show that the learning approach used in our ERP courses was encouragingly accepted by the students and stipulated what was expected, the knowledge and skills required to adapt in the future to the practical tasks of their new profession. In addition, the outcomes of the survey indicate that, through an integrated and integrative thinking mentality, students have attained new knowledge 
and skills in the use of ERP, as well as in the field of integrated thinking.

The results of the implemented study could be affected by various factors. They are influenced due to the partiality of the participants, as the survey was based on self-assessment statements. The study was conducted in business study programs with students who have basic technical skills and business knowledge, therefore, the perception of ERP may differ if the experiment was applied to students with other types of knowledge. The study was conducted using a national ERP solution; for that reason, we are not able to generalize the outcomes to all ERP solutions. We can also add that more data would be collected from more students; a situation in which more advanced processing tools would be needed to get a better perspective on the new teaching methods and even to make predictions regarding the evolution of students.

As the result of the implemented study, as being encouraging to the adoption of an integrated and integrative thinking as a complement to the traditional learning practices, our research in this field will continue. Regarding future work, we will investigate the acceptance and adequacy of ERP by simulating games in a mixed reality environment. In addition, we will use largely the information extracted from eLearning platform logs.

\section{Acknowledgments}

The authors would like to thank our students for choosing this course and participating in the study. Dr. Bresfelean would like to thank for the support of UEFISCDI national research project PN-III-P1-1.2-PCCDI2017-0884.

\section{References}

Abbott, W., \& Nantz, K. (2012). Building Students' Integrative Thinking Capacities: A Case Study in Economics and History. Issues in Integrative Studies.

Aldayel, A. I., Aldayel, M. S., \& Al-Mudimigh, A. S. (2011). The Critical Success Factors of ERP implementation in Higher Education in Saudi Arabia: A Case Study. Journal of Information Technology and Economic Development, 2(2), 1-16.

Alves, M. do C., \& Matos, S. I. A. (2013). ERP adoption by public and private organizations - a comparative analysis of successful implementations. Journal of Business Economics and Management, 14(3), 500-519.

Antonucci, Y. L., Corbitt, G., Stewart, G., \& Harris, A. L. (2004). Enterprise Systems Education: Where Are We? Where Are We Going? Journal of Information Systems Education, 15(3), 227.

Becerra-Fernandez, I., Murphy, K. E., \& Simon, S. J. (2000). Integrating ERP in the 
business school curriculum. Communications of the ACM, 43(4), 39-41.

Beranič, T., \& Heričko, M. (2019). Introducing ERP Concepts to IT Students Using an Experiential Learning Approach with an Emphasis on Reflection. Sustainability 2019, Vol. 11, Page 4992, 11(18), 4992.

Blount, Y., Abedin, B., Vatanasakdakul, S., \& Erfani, S. (2016). Integrating enterprise resource planning (SAP) in the accounting curriculum: a systematic literature review and case study. Http://Dx.Doi.Org/10.1080/09639284.2016.1138136, 25(2), 185-202.

Bodisco, T. A., \& Palmer, S. (2020). Presentation and evaluation of a new graduate unit of study in engineering product development. Sustainability (Switzerland), 12(14), 1-14.

Bologa, A. R. (2007). ERP for Romanian Higher Education. Informatica Economica, XI(3), 100-103. https://ideas.repec.org/a/aes/infoec/vxiy2007i3p100103.html

Bradford, M., \& Florin, J. (2003). Examining the role of innovation diffusion factors on the implementation success of enterprise resource planning systems. International Journal of Accounting Information Systems, 4(3), 205-225.

Brehm, N., Haak, L., \& Peters, D. (2009). Using FERP Systems to Introduce Web Service-Based ERP Systems in Higher Education. Lecture Notes in Business Information Processing, 37 LNBIP, 220-225.

Bresfelean, V. P., Res, M.-D., \& Comes, C.-A. (2015). Pre-existent Training: Opportunities to Increase the Success Rate of ERP Systems Implementations for Sustainable Development Business. Journal of Studies in Education.

Carifio, J., \& Perla, R. (2008). Resolving the 50-year debate around using and misusing Likert scales. Medical Education, 42(12), 1150-1152.

Cohen, D. S. (2005). Why Change Is an Affair of the Heart. CIO, 19(5).

Dalveren, Y. (2014). Using E-learning in Enterprise Resource Planning (ERP) Training: A Case Study to Assist Curriculum Designers in Turkey. Procedia Social and Behavioral Sciences, 116, 1353-1357.

Duc, M. Le. (2013). Adoption of Enterprise Resource Planning systems in university education curricula - a case study. 17th EBES Conference-Venice, 
October 15-17, 2015, 2009.

Estacio, R. R., \& Raga, R. C. (2017). Analyzing students online learning behavior in blended courses using Moodle. Asian Association of Open Universities Journal, $12(1)$.

Faisal Anwar, A. H. M. (2012). The use of students' feedback for effective learning in engineering units. International Journal of Learning, 18(4), 131-142.

Gerogiannis, V., \& Fitsilis, P. (2006). A Project-Based Learning Approach for Teaching ERP Concepts. The International Journal of Learning: Annual Review, 12(8), 261-268.

Haddara, M. (2018). ERP systems selection in multinational enterprises: a practical ERP systems selection in multinational enterprises: a practical guide guide. International Journal of Information Systems and Project International Journal of Information Systems and Project Management Management, 6(1).

Hardaway, D., Harryvan, R., Wang, X. (Frank), \& Goodson, J. (2016). Partnering with Practice: How Partnerships can be Developed, Shared and Managed. Communications of the Association for Information Systems, 38(1), 6.

Hawking, P., Foster, S., Ding, H., \& Zhu, C. (2008). ERP education in China: The tale of two paths. In S. Xu, L, Tjoa, A and Chaudhry (Ed.), Research and Practical Issues of Enterprise Information Systems II (Vol. 255, pp. 893-905). IFIP International Federation for Information Processing (255).

Hepner, M., \& Dickson, W. (2013). The Value of ERP Curriculum Integration: Perspectives from the Research. Journal of Information Systems Education, 24(4), 309-326.

Humpl, S. (2020). Professionalisation in ERP selection. CEUR Workshop Proceedings, 2581.

Iriberri, A., Kwon, O., \& Henson, J. (2015). Integrating an Erp into the Curriculum at A Business School: The Students' Perceptions of SAP. Academy of Educational Leadership Journal, 19(2).

Kilic, H. S., Zaim, S., \& Delen, D. (2015). Selecting "the best" ERP system for SMEs using a combination of ANP and PROMETHEE methods. Expert Systems with Applications, 42(5), 2343-2352. 
Kumpas-Lenk, K., Tucker, B. M., \& Gupta, R. (2014). Validation of a unit evaluation survey for capturing students' perceptions of teaching and learning: A comparison among Australian and Estonian higher education students. Studies in Educational Evaluation, 43, 178-185.

Lacurezeanu, R., \& Bresfelean, V. P. (2021). Making a Multi-criteria Analysis Model for Choosing an ERP for SMEs in a KM World. In O. H. Dzitac I., Dzitac S., Filip F., Kacprzyk J., Manolescu MJ. (Ed.), Intelligent Methods in Computing, Communications and Control. ICCCC 2020. Advances in Intelligent Systems and Computing, vol 1243. (pp. 257-273). Springer, Cham.

Lacurezeanu, R., Stanca, L., \& Chis, G. S. (2018). Introduction of Digital Competences in Romanian Higher Education - The Profile Of Economy Students In The Digital Era. The 17th International Conference on Informatics in Economy (IE 2018). https://www.conferenceie.ase.ro/index.php/previous-conferences/ie-2018the-17th-international-conference-on-informatics-in-economy/

Leyh, C., Strahringer, S., \& Winkelmann, A. (2012). Towards Diversity in ERP Education - The Example of an ERP Curriculum. Lecture Notes in Business Information Processing, 105 LNBIP, 182-200.

Magnusson, J., Oskarsson, B., Gidlund, A., \& Wetterberg, A. (2009). Process Methodology in ERP-Related Education: A Case from Swedish Higher Education. Lecture Notes in Business Information Processing, 37 LNBIP, 214-219.

Martin, R. (2007). How successful leaders think. Harvard Business Review, 85(6). https://doi.org/10.1108/sd.2007.05623kad.006

Meade, N., \& Islam, T. (2006). Modelling and forecasting the diffusion of innovation - A 25-year review. International Journal of Forecasting, 22(3).

Noaman, A. Y., \& Ahmed, F. F. (2015). ERP Systems Functionalities in Higher Education. Procedia Computer Science, 65, 385-395.

Norman, G. (2010). Likert scales, levels of measurement and the "laws" of statistics. Advances in Health Sciences Education 2010 15:5, 15(5), 625-632.

Oliver, B., Tucker, B., Gupta, R., \& Yeo, S. (2008). eVALUate: an evaluation instrument for measuring students' perceptions of their engagement and learning outcomes. Https://Doi.Org/10.1080/02602930701773034, 33(6), 619-630.

Oliver, J., Vesty, G., \& Brooks, A. (2016). Conceptualising integrated thinking in 
practice. Managerial Auditing Journal, 31(2).

Raga, R., \& Raga, J. (2017). Monitoring Class Activity and Predicting Student Performance Using Moodle Action Log Data. International Journal of Computing Sciences Research, 1(3), 1-16.

Raicu, A., Raicu, G., Raicu, A., \& Raicu, G. (2015). Innovation in engineering education through computer assisted learning and virtual university model. $M S \& E$, 95(1), 012126.

Riel, J., \& Martin, R. (2017). Creating great choices: a leaders guide to creating great choices. Harvard Business Review Press.

Rogers, E. M. (2003). Diffusion of Innovations (5th ed.). Simon and Schuster.

Sánchez-Prieto, J., Trujillo-Torres, J. M., Gómez-García, M., \& Gómez-García, G. (2021). Incident Factors in the Sustainable Development of Digital Teaching Competence in Dual Vocational Education and Training Teachers. European Journal of Investigation in Health, Psychology and Education 2021, Vol. 11, Pages 758-769, 11(3), 758-769.

Scaife, M., \& Rogers, Y. (1996). External cognition: How do graphical representations work? International Journal of Human Computer Studies, 45(2).

Scott, J. (1999). ERP Effectiveness in the Classroom: Assessing Congruence with Theoretical Learning Models. AMCIS 1999 Proceedings.

Shanneb, A. (2020). Incorporating SAP® ERP Training into Industrial College Education: A Usability Evaluation Incorporating SAP ® ERP Training into Industrial College Education: A Usability Evaluation. International Journal of Education and Management Engineering, 5, 1-9.

Shehab, E. M., Sharp, M. W., Supramaniam, L., \& Spedding, T. A. (2004). Enterprise resource planning: An integrative review. Business Process Management Journal, 10(4), 359-386.

Sinha, A., \& Singh, A. (2020). Role of ERP and Total Quality Management in Education. Zenodo.Org. https://doi.org/10.5281/ZENODO.4292157

Sobral, S. R., \& Sobral, M. (2021). Computer Education and Third Age Universities: A Systematic Review. International Journal of Environmental Research and Public Health 2021, Vol. 18, Page 7390, 18(14), 7390. 
Sung, M., \& Yang, S.-U. (2008). Toward the Model of University Image: The Influence of Brand Personality, External Prestige, and Reputation. Journal of Public Relations Research, 20(4), 357-376.

Tiron-Tudor, A., Deliu, D., Farcane, N., \& Dontu, A. (2021). Managing change with and through blockchain in accountancy organizations: a systematic literature review. Journal of Organizational Change Management, 34(2), 477-506.

Tucker, B., Oliver, B., \& Gupta, R. (2013). Validating a teaching survey which drives increased response rates in a unit survey. Teaching in Higher Education, 18(4), 427-439.

Wang, M., \& Hwang, D. (2011). An Innovative Framework of Integrating ERP into IS 2010 Model Curriculum. Communications of the IIMA, 11(3).

Wimmer, H., \& Hall, K. (2016). A Technical Infrastructure to Integrate Dynamics AX ERP and CRM into University Curriculum. Information Systems Education Journal, 14(1), 48.

Winter, J. F. C. de, \& Dodou, D. (2010). Five-Point Likert Items: t test versus Mann-Whitney-Wilcoxon (Addendum added October 2012). Practical Assessment, Research, and Evaluation, 15(1), 11.

Yoon, S. (2020). A study on the transformation of accounting based on new technologies: Evidence from korea. Sustainability (Switzerland), 12(20).

Zeng, Y. R., Wang, L., \& Xu, X. H. (2017). An integrated model to select an ERP system for Chinese small- and medium-sized enterprise under uncertainty. Technological and Economic Development of Economy, 23(1), 38-58.

Zhang, Y. (2011). Block-Based Design ERP Curriculum Teaching. Communications in Computer and Information Science, 244 CCIS(PART 2), 84-90.

Zhang, Z., Lee, M. K. O., Huang, P., Zhang, L., \& Huang, X. (2005). A framework of ERP systems implementation success in China: An empirical study. International Journal of Production Economics, 98(1), 56-80.

Zornada, L., \& Velkavrh, T. B. (2005). Implementing ERP systems in higher education institutions. Proceedings of the International Conference on Information Technology Interfaces, ITI, 307-313. 